\title{
EDITORIAL
}

\section{Colluding With the Decline of Continuity}

\author{
Jobn J. Frey III, MD, Associate Editor
}

Ann Fam Med 2018;16:488-489. https://doi.org/10.1370/afm.2322.

"Y ou can pretend to know, you can pretend to care, but you can't pretend to be there."

For most of the 20th century, "being there" was a standard for family doctors in their communities and practices. General practitioners were physicians who went from house calls to nursing homes to offices to hospitals in the course of their everyday work. They knew the terrain of their communities. Persistence across place was an assumption and concerns about giving up some of that territory-specifically the hospital-were at the heart of the decades-long debate about creating family medicine as a specialty. ${ }^{2}$

As a young family doctor, Loxterkamp expressed some confusion about the meaning of the term continuity but came down on the side of presence, trust, reliability, responsibility, and endurance while acknowledging the limits, even then, of "being there when we can, when we are not defeated by sheer exhaustion, the rush of our job, a mistaken focus, the blush of sentiment, or the cry of our own neglected needs." ${ }^{13}$ In that regard, he presaged the discussion about scope of practice, burnout, uncertainty, guideline adherence, and all of the other terms that are affecting the enormously complex issues of work and personal and professional struggle in the practice and purpose of family medicine.

Continuity between patients and physicians inevitably affects issues of trust and safety. ${ }^{4,5}$ Sixty years ago, Balint captured the loss of trust best in the phrase "the collusion of anonymity" to describe the confusion a patient and their family feel when "vital decisions are made without anyone feeling fully responsible for them,"6 and why there is often confusion when a patient asks "who is my doctor?" Fifteen years ago, Saultz and Lochner systematically reviewed the informational, longitudinal, and interpersonal aspects of defining continuity. They found that most studies comparing noncontinuity with continuous care support continuity as a factor for lower cost, better prevention, and higher physician and patient satisfaction. ${ }^{7.8}$ Since the time of their analysis, the practice of family medicine and primary care have changed dramatically, and with those changes, perhaps the significance and consequences of continuity have changed as well. Discussion about continuity has moved away from the nature of personal relationships with patients, the role of being there, and how those relationships play an essential role in health care decisions in a person's life to whether "handoffs" are smooth or whether electronic health records are complete. What does it mean to have continuity with a team or with a system more focused on managing disease than on meeting the needs of individuals and families for integrated, personalized care and connection? Family physicians run the risk of becoming enmeshed with clinical data systems and electronic health records and complex discussions about teams of care instead of focusing on individual relationships.

The article by Bazemore et al in this issue of Annals ${ }^{9}$ examines the association of 4 different physician-level continuity measures, based on Medicare claims data, with health care expenditures and hospitalizations. The observed lower rates of hospitalization and health care spending, controlling for patient and physician characteristics, provides high-level evidence of the importance of continuity in a nationally representative sample of patients particularly likely to benefit from an ongoing relationship with a primary care physician. This research begs the question of why primary care has been moving away from continuity in spite of evidence that shows that it is an essential component of any quality system of care and an anchor factor of satisfaction for family physicians?

Although the presence or lack of continuity remains central-a "defining characteristic of primary care" as Bazemore et al put it-the replacement of continuity by convenience for both patients and doctors demands serious discussion. Otherwise the concept will, by default, cease to be central to both education and practice. While pointing fingers at health systems, insurance products, population changes, and society in general, the discipline needs to understand how it has colluded with the disintegration of continuity in the education of residents and students. Rather than promoting continuity of care as the essential and distinguishing value around which education is built, residency programs have experienced increasing fragmentation which deemphasizes the primacy of the family practice center and the community as the 
focus of learning. If continuity is threatened, residency education needs radical restructuring to avoid a persistent drift to a more circumscribed scope of practice in health systems. To do nothing is a passive admission that either the fight is not worth it or that an educational system still primarily driven by productivity and hospital financial needs is "good enough."

If educational leaders not only permit, but encourage subspecialization, limiting continuity may become the norm. Hospitalists, sports medicine physicians, maternal fetal medicine, women's health, urgent care, palliative care, geriatrics, are all seen as natural evolution of family medicine. These days, the question new residents are asked is not where they are interested in practicing, but what area of focus they have and what "tracks" they will follow. Rather than serving as a counterculture, as Gayle Stephens described them, ${ }^{10}$ departments and residency programs may be complicit in the compartmentalization of health care. Although residency education may provide a generalist mindset for family physicians, the lack of continuity with patients and families through early subspecialty career choice could trap residents into narrowing their careers early rather than exploring broader options as they gain experience.

If graduate education in family medicine were to be reimagined in today's world, and continuity with patients, families, and communities were to be a guiding principle, the structure of what currently exists would require radical transformation. Carney et al describe in great depth the challenges in the current structure which impair residents experiencing continuity with patients. ${ }^{11}$ Although teams are a natural strategy for improving continuity, residents must actively participate with those teams and have the time and training to engage in care planning and strategies. Gupta and colleagues outline strategies that should be used to maintain continuity as a focus for residency education, ${ }^{12}$ and the problem is not isolated to the United States. ${ }^{13}$ The challenges of the financial disconnect between funding sources and requirements and the skills and training necessary for care in the 21st century have been addressed by the National Academies of Science Engineering and Medicine in their 2014 report. ${ }^{14}$

Losing or designing away a focus on continuity of care in training and practice has real consequences for physicians and patients. Physicians have already entered into an era of dysphoria driven by any number of factors that threaten the recruitment of medical students into the primary care specialties. One of the few areas of genuine satisfaction for family physicians has always been the connection with and care of patients and families over time. The loss of that connection will not be balanced by income or lifestyle fixes, and risks compromising the values for which family medicine was created in the 1960s. For patients, the loss of continuity, as the research by Bazemore and colleagues implies, is likely to result in more cost and less quality which, ultimately, will continue to drive the US health system toward economic unsustainability. Family medicine will then have become part of the problem, not part of the solution.

To read or post commentaries in response to this article, see it online at http://www. AnnFamMed.org/content/16/6/488.

Key words: primary health care; continuity of care; education, medical

Submitted September 4, 2018; submitted, revised September 25, 2018; accepted October 2, 2018.

\section{References}

1. Phillips WR, Haynes DG. The domain of family practice: scope, role, and function. Fam Med. 2001;33(4):273-277.

2. Hunt VR. The unifying principles of family medicine: a historical perspective. R I Med. 1993;76(7):351-360.

3. Loxterkamp D. Being there: on the place of the family physician. J Am Board Fam Pract. 1991:4(5):354-360.

4. Tarrant C, Dixon-Woods M, Colman AM, Stokes T. Continuity and trust in primary care: a qualitative study informed by game theory. Ann Fam Med. 2010;8(5):440-446.

5. Rhodes P, Sanders C, Campbell S. Relationship continuity: when and why do primary care patients think it is safer? British J Gen Pract. 2014;64(629):e758-764.

6. Balint M. The Doctor, His Patient and the Illness. London, UK: Churchill Livingstone; 1957.

7. Saultz JW, Lochner J. Interpersonal continuity of care and care outcomes: a critical review. Ann Fam Med. 2005;3(2):159-166.

8. Saultz JW, Albedaiwi W. Interpersonal continuity of care and patient satisfaction: a critical review. Ann Fam Med. 2004;2(5): 445-451.

9. Bazemore A, et al. Higher primary care physician continuity is associated with lower costs and hospitalizations. Ann Fam Med. 2018; 16(6):490-491.

10. Stephens GG. Family medicine as counterculture. Fam Med. 1989; 21(2):103-109.

11. Carney PA, Conry CM, Mitchell KB, et al. The importance of and the complexities associated with measuring continuity of care during resident training: possible solutions do exist. Fam Med. 2016; 48(4):286-293.

12. Dubé K, Gupta R, Kong M, Knox M, Bodenheimer T. Continuity of care in residency teaching practices: lessons from "bright spots". Perm J. 2018;22:18-28.

13. Hebert I. Continuity of care in family medicine: from clinical clerkship to practice. Can Fam Physician. 2012;58(6):e308-309, 628-309.

14. National Academies of Sciences, Engineering, and Medicine. Recommendations: graduate medical education that meets the nation's health needs recommendations, goals, and next steps. http:// www.nationalacademies.org/hmd/Reports/2014/Graduate-MedicalEducation-That-Meets-the-Nations-Health-Needs/Recommendations. aspx. Published Jul 29, 2014. 